\title{
New Green Oil-Field Agents
}

\author{
Arkadiy Zhukov and Salavat Zaripov \\ RED Center, GC «Mirrico» \\ Russian Federation
}

\section{Introduction}

The current state of environmental conditions on planet Earth is a substantial basis for modification as the cleaning and disposal of waste and emissions, and fundamental changes in processes and technology industries. Recently, the transition from administrative methods required to control unwanted emissions and destroy formed by chemical processes harmful substances to a fundamentally different method - the method of green chemistry. Green chemistry in its best incarnation - is an art form that allows not just to get the right stuff, but ideally to get it in a way, which does not harm the environment at any stage of production. Of course, the substance itself must also be friendly to biosphere.

Like any perfected motion requires less force for its implementation and use of methods of green chemistry leads to a reduction of production costs, if only because they do not need to enter the stage of destruction and recycling of hazardous by-products, used solvents and other wastes, as they are simply not formed. Reducing the number of stages leading to energy savings, and this is also a positive impact on environmental and economic assessment of the production. It is important to note that the view of ongoing research from the viewpoint of green chemistry can be useful in purely scientific terms. Often, such a change of paradigm allows scientists to see their own research in a new light and open up new opportunities that benefit science in general.

\section{How to implement "green" process}

Introduction is a difficult task even for developed countries. In Britain, for example, is now a strongly encouraged interaction between scientists and chemical technologists. Even a joint center for the introduction of "green chemistry» has been created. At the University of Nottingham for the first time in the world to teach a course on green chemistry for chemistry students and chemists and technologists of the last school year. Undergraduates are taught to consider the chemical process as a whole and not fragmented. It is not enough that the specialist can choose the traditional or the most expensive reagent for the industrial synthesis, it is necessary to keep in mind the entire process from beginning to end. The primary sources of the initial reagent (extracted or renewable) as the reagent prepared, nuclear reaction efficiency, solvents, minimizing their use or non-toxic solvents, the selectivity of output allows the costs of by-products to be at a low level, what will ensure the viability of the process. 


\section{Oil production}

Modern man can not exist without the consumption of large amounts of energy. Historical progress of the international community was determined by first of all that mankind has managed to use for practical purposes fossil fuels: coal, oil and natural gas. In the 60s of last century, about three-quarters of world consumption of fuel wood and covered with vegetable substitutes, almost a quarter - coal. The share of oil and gas accounted for about $1 \%$. At the end of the century came the "era of coal." In 1900, its share in energy balance (FEB), the world has risen to $57 \%$, the share of oil and gas was at $2.3 \%$ and $0.9 \%$.

Until the mid-nineteenth century, oil was extracted in small amounts (2-5 tons per year) from shallow wells near its natural outlets to the surface. The Industrial Revolution, based on extensive use of steam engines, determined the broad demand for lubricants and light sources (kerosene). There was an increased demand for oil. With the introduction in the late 60-ies, oil well drilling global oil production tenfold increased from 2 to 20 million tonnes by the end of the nineteenth century. In 1900, oil was extracted in 10 countries: Russia, U.S., Dutch East India, Romania, Austria-Hungary, India, Japan, Canada, Germany, Peru. Almost half of total world oil production goes to Russia (9927 tonnes) and USA (8334 tonnes). Throughout the twentieth century. global oil consumption continued to grow rapidly.

The effectiveness of development of oil reduces the loss of its reserves in the subsoil, as not all stocks can be learned for technological reasons: falling well production rates (at least the fall of the reservoir pressure), water content and total depletion of deposits, etc. In order to increase production using different methods of influencing the oil reservoirs. So, in 1994, with the help of thermal, chemical, gas and other methods to increase the recovery factor in the world received an additional 93.4 million tons of oil. That same year, the application of new methods of enhanced oil recovery in the U.S. has allowed to obtain an additional 34.89 million tons, Russia - 11.55 million tonnes of oil. On Romashkino field through the use of enhanced oil recovery techniques more oil in 1993 was $26 \%$ with respect to all oil from the field in the same year. However, in recent years the average rate of oil recovery in Russia as a whole on all deposits decreased. Now in more than four fifths of all recoverable oil wells are produced fluids with electric-submersible pumps and gas lift.

\section{Environmental issues in oil and gas sector}

Oil and gas industry has a negative impact on all components of the environment, especially in northern areas. During the drilling of wells, construction of buildings and land communications in areas of permafrost after the integrity of the protective vegetative cover increases the heating of the soil to great depth. Thermokarst processes cause melting of underground ice. Because of this, the formation of the earth surface subsidence, deep channels, gullies, formation of new lakes, marshes and valleys, which in turn increases the likelihood of deformation of the pipe and breaks. In the process of production, preparation, transportation, storage, processing and utilization of oil and gas produces toxic chemicals. Contain their bowels pollutes the waste water, natural landscapes and water bodies. Thus, in the West Siberian petroleum province in many areas of $\mathrm{Ob}$ river and its tributaries, the content of organic pollutants exceeds the MPC by ten times. The volume of water consumed by a drilling rig, for example, in the gas industry, ranging from 25 to $120 \mathrm{~m} 3$ per day. Daily volume of wastewater generated is $20-40 \mathrm{~m} 3$ per well. The annual volume of drilling 
wastewater averaging 777 thousand $\mathrm{m} 3$, including cuttings 221.9 thousand m3. Significant damage to aquatic ecosystems causing a flowing drilling and drilling fluid from the barns, accidents at oil pipelines and fishing facilities. Accidents on main oil and gas pipelines have a catastrophic impact on the environment. However, most of the Russian pipelines operated by longer regulatory period, it makes them targets of environmental risk. Thus, in Russia on gas pipelines from 1960 to 1990, there were 1,200 accidents. The accident at the Western Siberian oil product in 1989 led to a major train accident, accompanied by a powerful explosion, fire, and many large-scale casualties. In 1994, as a result of an accident on an oil pipeline in the Komi Republic were contaminated with large surface area and significant volumes of oil got into streams and rivers. Oil and gas facilities emit greenhouse gases, nitrogen oxides, sulfur dioxide and other toxic and natural hydrocarbons themselves.

The structure of the oil is changed for the worse. Despite the advances in technology, methods, Geophysics, effort and investments aimed at exploration, a large-scale increase in lung stocks are not observed, but on the contrary, the future of oil production is associated with heavy oil onshore, offshore production (including the Arctic) and production of deepsea oil. Russian oil and gas producers are is the second largest country after Saudi Arabia. Currently in Russia there is a problem structure of proven oil reserves: the current oil reserves, the share of hard-to-oil exceeded $60 \%$. In this regard, increased production of heavy oil: in 2005, was produced 42.5 million tons heavy and extra heavy oil. These are hard-to-oil, or mode of occurrence or the quality of raw materials. This category should also include most of the oil reserves in undergas deposits. If to this be added to the extraction yield in underdeveloped areas with difficult climatic conditions and the near absence of economic and transport infrastructure, the production could be on the verge of economic efficiency. To some extent, this is a world problem. The deterioration of the structure of inventories in the future will inevitably affect the price rise in oil

United States opened for the development of offshore deposits of the Pacific, Atlantic oceans, which have long been "locked up" officially "for environmental reasons." But after a major accident in the Gulf of Mexico in April 2010 on a platform of deep «Deep Horizon", Congress was forced to ban the further development of offshore fields until the development of regulations safety. There is no doubt that in the near future, the ban will be lifted, but the fact that the offshore fields have been opened for development, said that other more lucrative prospects of large-scale production in the U.S. has no land. In addition, in itself a step toward increasing production of deep oil suggests that the U.S. government are convinced that oil prices will remain high in the future, i.e. the proportion of hard-to-oil in world production will increase.

Renewable energy projects are actively promoted. The program of development of wind, solar and biofuels are set up all around the world. The leaders are the United States, China and the European Union. For example in Europe in 2020 is planned to increase the share of renewable energy to $20 \%$. Officially this is because "the reduction of human impact on climate change and reducing emissions of $\mathrm{CO} 2$ in the atmosphere." But in order for these programs earned, and renewable energy has become competitive, you need high prices for oil and gas. A rise in prices, in turn, negatively affects economic growth. With all that research on human impacts on climate are controversial, as there was much talk, so to some extent is illogical rush to develop renewable energy (with the creation of objective difficulties for the economy). On the other hand, if we take into account the possibility of 
reducing oil production in the next two decades, this increased interest in renewable energy is a logical and understandable.

\section{Oilfield chemicals}

Significant branch of the modern chemical industry is the manufacture of products used in the processes of the oil and oil transportation. Each year the requirements for this kind of reagents increasingly tightened, for example, to decrease the volume of product flow while increasing its efficiency. Below we will consider some classes of oilfield chemicals and provide examples of available commercial products, including meeting the requirements of "green chemistry».

\subsection{Demulsifiers}

In recent years, many deposits are opened in the late stage of development which has significant water content of the output.

As a result, commercial facilities pose serious technological challenges associated with the need to handle large quantities of water extracted simultaneously. Formation of emulsions during oil production is the main cause for large losses of oil, cost of transportation and preparation for recycling.

With increasing water content in oil at $1 \%$ of transportation costs increase by $3-5 \%$ for each transfer. In addition to costs directly in the oil industry, large volumes of water extracted along the way during transport cause the destruction of oilfield corrosion and environmental problems due to accidents of pipelines. Usually, the destruction of oil-water emulsion is heated addition of demulsifiers of this mixture.

Demulsifiers are currently anion (cation) active and nonionic surfactants: the block copolymers of ethylene oxide and propylene oxide, ethoxylated amines, higher fatty alcohols, alkylphenols, etc. Even with relatively low consumption of reagents (40-100 g/t) rather acute problem recycling of surface-active substances produced by many thousands of tons of the modern chemical industry.

Creating a "green" brands demulsifiers is justified not only environmental, but also with the economic position as a biodegradable agent does not require, or at least reduces the cost of cleanup and disposal of waste containing it. So do not consider the desire to create an "environmentally friendly" chemicals like fashion - it can actually lead to significant cost savings.

Here are some examples of such demulsifiers.

On the basis of wood chemical product manufacturing - tall oil, which consists of fatty acids (oleic, linoleic, palmitic) and resin acids: abietic, neoabietic, digidroabietic (Figure 1) by their ethoxylation demulsifiers were obtained, but tests showed their lower efficiency compared to demulsifier obtained ethoxylation of fatty acids.

On the basis of xylitol (derived from waste cotton plants, Figure 2) and synthetic fatty acids was obtained nonionic demulsifier, which showed a result of industrial tests of high efficiency. 


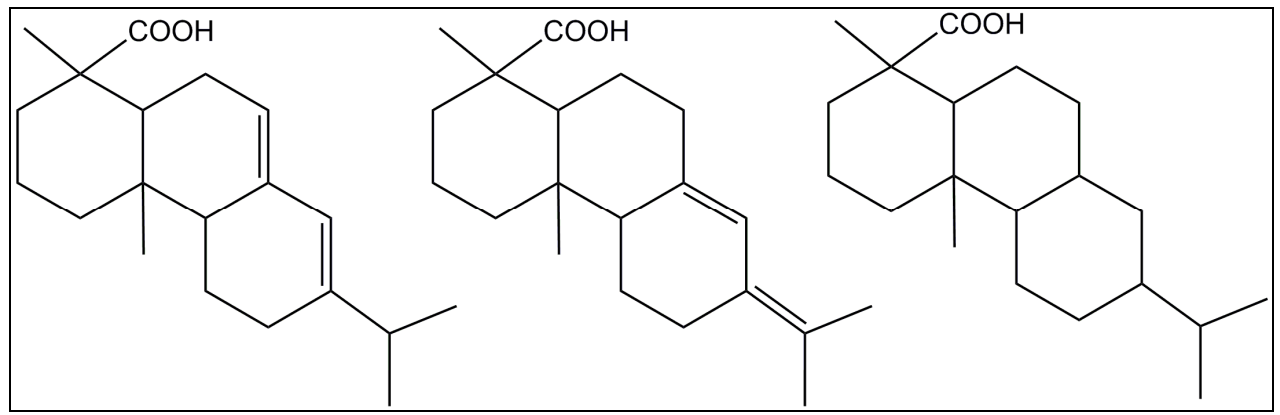

Fig. 1. Abietic acids

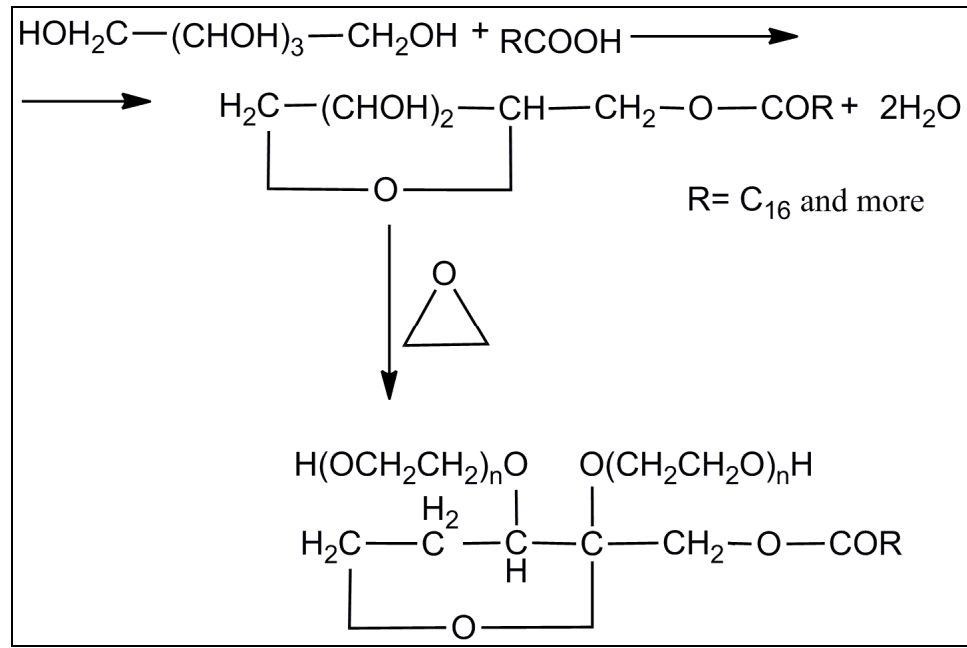

Fig. 2. Synthesis of xylitol derivatives

Promising "green" platform for demulsifiers is glycerol. Ethoxylation its esters (acetate, stearate), a number of new demulsifiers.

Despite the high efficiency of demulsifiers on the basis of alkyl phenols, their use should be limited due to toxicity of phenolic fragment.

It was found that emulsions are efficient destroyers of silicone derivatives that do not contain toxic groups, such as phenolic or aryl. Such compounds are promising for use in oil field chemistry.

Leading manufacturers of oilfield chemicals have in their product line, "green" demulsifiers, for example, Clariant offers a similar product under the brand «Phasetreat». Are patented cross-linked esters of glycerol and pentaerythritol.

There are patents in which as demulsifiers proposed use oligoglicosides containing alkyl radicals and oxyethylene-, oxypropylene-substituents. Specially negotiated their biodegradability. 
Demulsifier, patented Nalco (Figure 3) is not only biodegradable but also non-toxic compound.

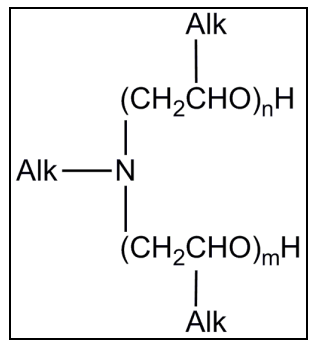

Fig. 3. Nalco' s demulsifier

The new direction is the use of dendrimers as demulsifiers, polyesters such as oxyalkylated Boltorn H20 and similar compounds (Figure 4).

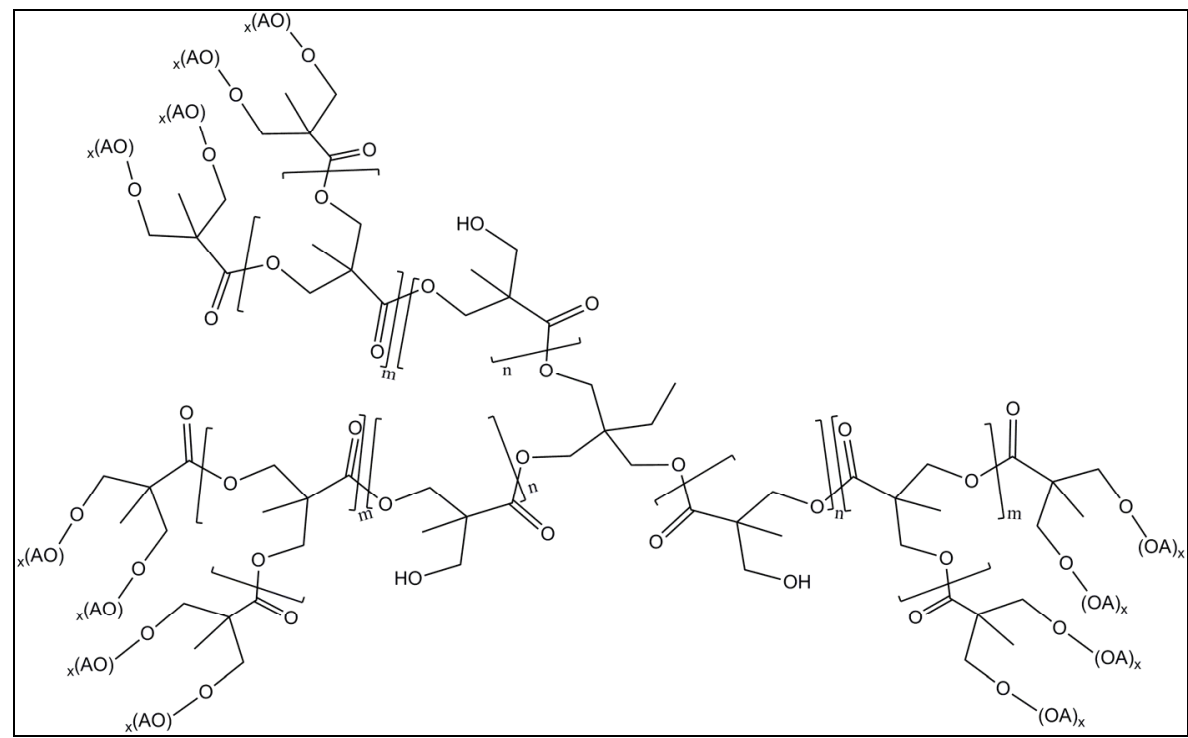

Fig. 4. Dendritic demulsifier

Despite the apparent complexity of its synthesis is rather simple.

Among the macromolecular platforms for the synthesis of interest are the macrocycles, such as calix[4]arenes. The possibility of fixing the macrocyclic rings in several spatial configurations, which provides a different position of substituents in space relative to each other (Figure 5), in combination with non-toxicity and ease of chemical modification of the lower rim of calixarenes makes promising molecular platforms for the creation on their basis of various reagents. Although many authors noted non-toxic derivatives of calixarene, yet the question of their biodegradability and metabolism studied enough; phenolic fragments, forming a skeleton macromolecules suggest that the degradation products could be toxic substances. 


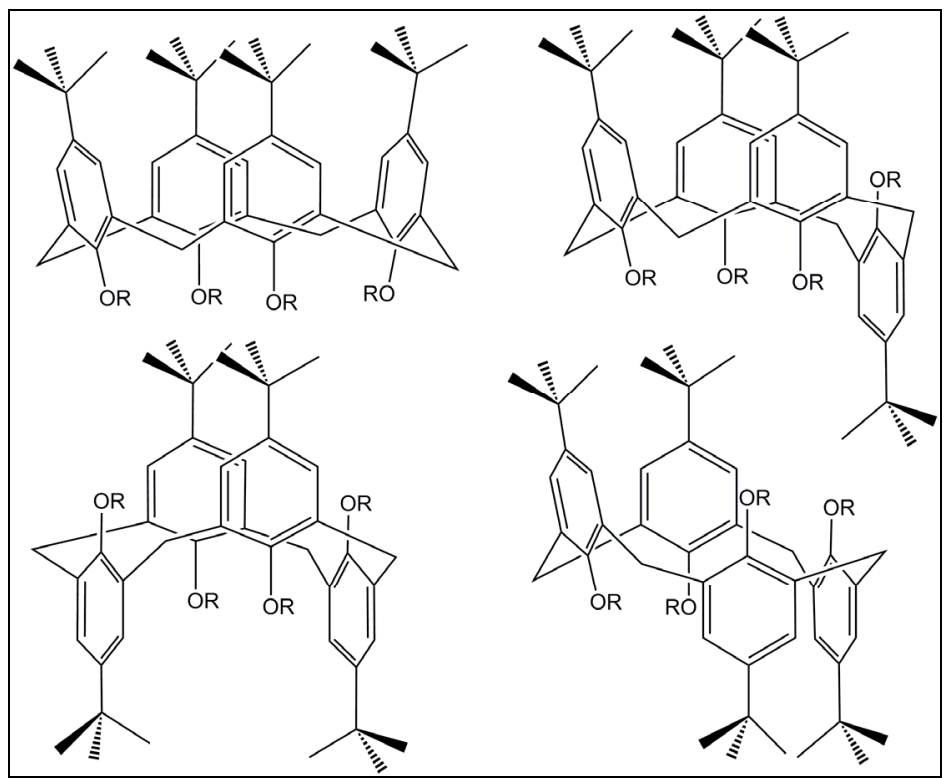

Fig. 5. The spatial configuration of calix [4] arene

The vast majority of demulsifiers are oxyalkylated derivatives (poly-) alcohols, acids and amines. Search and development of new products should be the rational choice of the starting material - the basis platform for oxyalkylation. Careful attention should be paid to renewable raw materials and waste paper and pulp, wood chemistry and food industry.

In addition to chemical methods of destruction of water-oil emulsions to improve and develop new techniques based on physical effects: heat, magnetic field, etc., as well as use the combined, integrated approach - the use of demulsifiers in conjunction with the hydrodynamic effects and magnetic devices.

\subsection{Corrosion inhibitors}

To date, corrosion processes create huge problems of the world economy. The most conservative estimate of about $10 \%$ annually smelted metal is to replenish losses due to corrosion. However, the main corrosion damage not associated with loss of large amounts of metal, but with the failure of themselves metal products and structures as a result of loss of essential properties (strength, ductility, electrical conductivity, tightness, thermal conductivity, etc.). Protecting metals from corrosion - a global international problem, so in all developed countries attached great importance to anti-corrosion materials in all its manifestations. At present there five areas to combat the corrosion of metals:

1. Design, manufacture and application of corrosion-resistant materials for the manufacture of pipelines and process equipment

2. Create a corrosion-resistant coatings and methods and technologies for processing of material surfaces exposed to the corrosive effect

3. Creation and application of corrosion inhibitors 
4. The use of electrochemical methods of protection of process equipment, pipelines and underground utilities in general

5. The package of measures for the development, design, construction and operation of pipelines and processing equipment in order to avoid the stress state of metal in which the corrosion processes are significantly faster.

Since the purpose of corrosion inhibitors do not exist, they are almost for each specific system, so the range of developed and produced by inhibitors of the world is enormous. In this world of science and technology known to more than 300000 names of individual chemicals and various technical formulations are classified as corrosion inhibitors. The volume of world production and consumption of corrosion inhibitors, lubricant additives is 4.4 million tons/year with a growth trend 5.5-6.0 million tons/year. Of this amount: the inhibition of oil, gas, produced water and other environments in oil and gas industry - 20$25 \%$, the preparation and processing of oil - $2-5 \%$, the inhibition of oil production and protection of oil-based, $65-75 \%$ for other needs (inhibition of acid cooling media, etc.) - 3-5\%. A large number of inhibitors used in pipeline transportation.

Corrosion inhibitors are the most diverse classes of organic and inorganic compounds, most of which is synthetic, not naturally occurring. It is obvious that the negative impact on the biosphere biologically hostile, recalcitrant compounds can not be overestimated, especially in a wide range of use of a reagent. The problem of corrosion of equipment, in particular oil field, is successfully solved, but to date there is no product that simultaneously satisfies all the requirements of the requirements: high efficiency, low cost, versatility and environmental safety. In light of this ever being the development of new corrosion inhibitors, which would be advantageous to differ from the existing not only the efficiency of inhibition, but also environmental safety.

For example, a corrosion inhibitor designed on the basis of waste vegetable oil that contains no toxic compounds and are low cost at a degree of protection of $78-95 \%$ depending on the environment.

BASF's proposed "green" corrosion inhibitors based on propargyl alcohol, known under the trade name Korantin ${ }^{\circledR}$ PM (Figure 6).

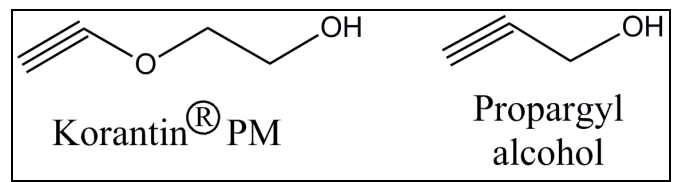

Fig. 6. BASF's corrosion inhibitors

Their most significant differences is not only cheap and nontoxic, but high inhibitory activity, 2-3 times exceeding some used products.

Company Cortec patented volatile corrosion inhibitor, a major component of which is ammonium benzoate - a non-toxic compound to the environment. The use of such compounds is justified in the manufacture of new modern packaging materials to prevent not only mechanical damage and corrosion of metal products during transportation and storage. 
It is known that the salts of chromium (III) are used as components of an effective corrosion inhibitors of metal products, but their use should be limited due to toxicity. Creating a less risky alternative to trains - the use of titanium salts in combination with oxidants such as hydrogen peroxide and the use of mono-, oligo-and polysaccharides as film-forming component. Described as an inhibitor of the phosphoric and boric acids with much less toxicity.

The problem of corrosion protection equipment, operated in hostile environments such as seawater, is quite serious. Offshore drilling and production of oil and gas offshore require not only high but also low toxicity and biodegradable oil-reagent did not affect the indigenous inhabitants of the marine flora and fauna. Found that many of the known corrosion inhibitors, even at a concentration of less than $1 \mathrm{ppm}$ inhibit the growth of algae. Preferably, the inhibitor is biodegradable at least $60 \%$ within 28 days after release to the environment. Also an important requirement is that sufficient hydrophilicity to minimize the bioaccumulation in adipose tissue, since lipophilic substances tend to accumulate as they move up the food chain.

Established that the imidazolines are not only effective inhibitors of corrosion, but also promising from an environmental point of view of satisfying the rigorous standards of toxicity. They do not contain phosphorus and sulfur atoms, and therefore are considered more "environmentally friendly". However, this does not mean that the substance is completely harmless, it is a very low toxicity at relevant concentrations.

One of the leading companies engaged in the development and manufacture of oilfield chemicals - Baker Huges proposed as corrosion inhibitors imidazolines (Figure 7)

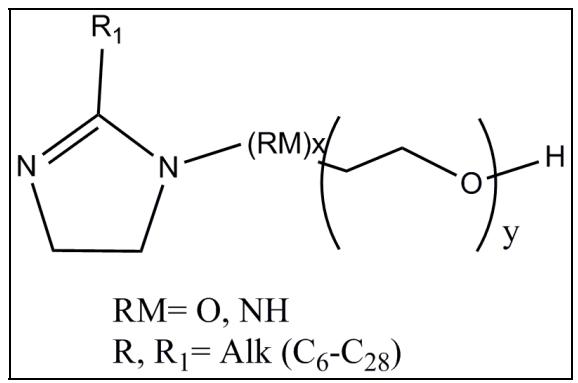

Fig. 7. Imidazoline derivatives- corrosion inhibitors

In the product line, the Russian company also has Mirrico anticorrosive agents on the basis of imidazolines on brand Scimol.

To protect the equipment with high concentrations of hydrogen sulfide and carbon dioxide proposed a corrosion inhibitor, which is a cyclic lactone (Figure 8) disaccharide ester and fatty acid obtained by enzymatic synthesis using the culture of Torulopsis apicola relevant material: oligo-and polysaccharides, saturated / unsaturated fatty acids oils, fats and other substances of plant or animal origin.

Along with a significant inhibitory effect observed with the following positive aspects: easy dispersibility in water, good adsorption on metal surfaces for values of $\mathrm{pH} 5.3$ or lower, non-inflammability and significantly less toxicity compared to known inhibitors. 


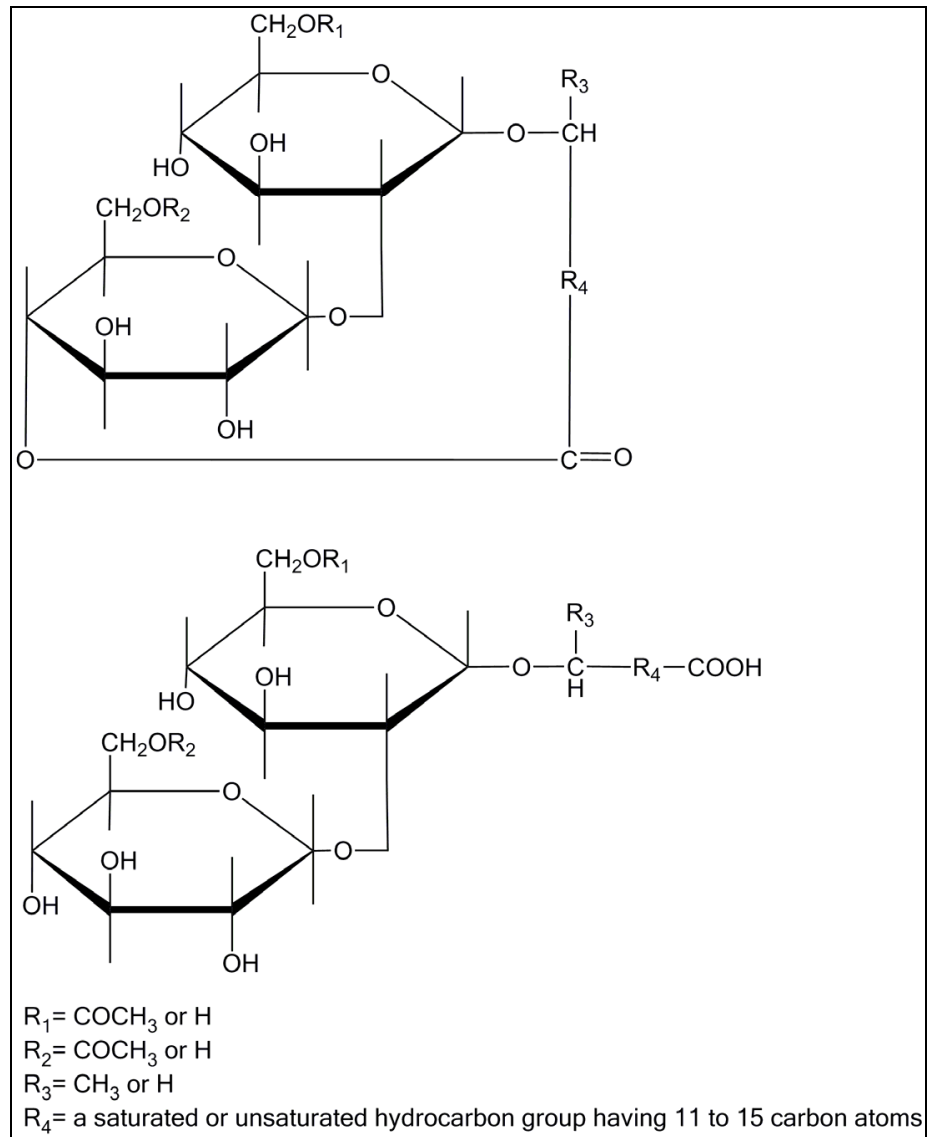

Fig. 8. Corrosion inhibitors based on oligo-and polysaccharides

Despite the variety of substances used as corrosion inhibitors, the most promising in terms of 'green' chemistry, are substances of natural origin and their various derivatives.

One of the main features of oilfield chemicals is their variety, caused by various conditions of oil production, changing the composition of crude oil and its associated waters. It often happens that the composition of oil in the well is so unique that it has required the selection of specific agents with the optimal dose is for a particular hole. The problem of corrosion of oilfield equipment depends on the chemical composition of the medium in which it is located: it is saturated salt solutions and contain significant amounts of hydrogen sulfide and mercaptans, water-oil emulsion and produced water with dissolved carbon dioxide, so the selection and creation of appropriate reagents is often a nontrivial task.

\subsection{Scale inhibitors}

The present stage of oil production is characterized by the need to make the surface of the vast amounts of associated water reservoir as well as injected in the reservoir to maintain pressure. 
As a result of flooding of the output at all stages of oil is the formation of salt deposits. Accumulating in the production strings on the surface of downhole pumping equipment and systems infield collection and preparation of oil, salt deposits not only cause great material costs in the process of removing them, but also to a significant loss in oil production.

The effectiveness of measures to combat the deposition of salt depends on an integrated approach to solving this problem. Need to know the physical and chemical processes and the causes of salt formation, taking into account the geological and physical conditions of occurrence of oil, human events and features of the development of oil and gas deposits and operating wells. The key areas for the deposition of salts from oil should be warning them, as a permanent measure, based on the best technological solutions that require scientific and methodological generalizations and systematic approach.

Based on the economic viability, depending on the conditions and characteristics of reservoir development, availability of raw materials, availability of technical resources and other factors may have different ways of dealing with this phenomenon, but in practice the problem of oil-field warning of salt deposits is decided mainly by inhibitor protection of wells and equipment .

Historically, the dominant classes of products inhibiting scaling in oil and gas production were phosphorous substances (eg aminomethylenephosphonates and phosphonic acids) and synthetic water soluble polymers such as polimaleates, polyacrylates, polisulfonates. Their main disadvantages are toxic to the environment and bioundegradability. The use of both classes of inhibitors are more tightly constrained as a result of legislative control. In recent years, the market introduced the latest "green" inhibitors: poly (amino acid) and chemically enhanced natural materials. This class of products has a low environmental toxicity, but the use of these inhibitors is still low because of the difficulty of their synthesis and significant economic costs compared with existing technologies.

Company AkzoNobel has been developed a new class of materials - hybrid polymers (copolymers of polysaccharides and polycarboxylic acids), (Figure 9) which combine the advantages of a single molecule, and synthetic and natural materials, the lack of benefit other than some of the restrictions currently known "green" products.

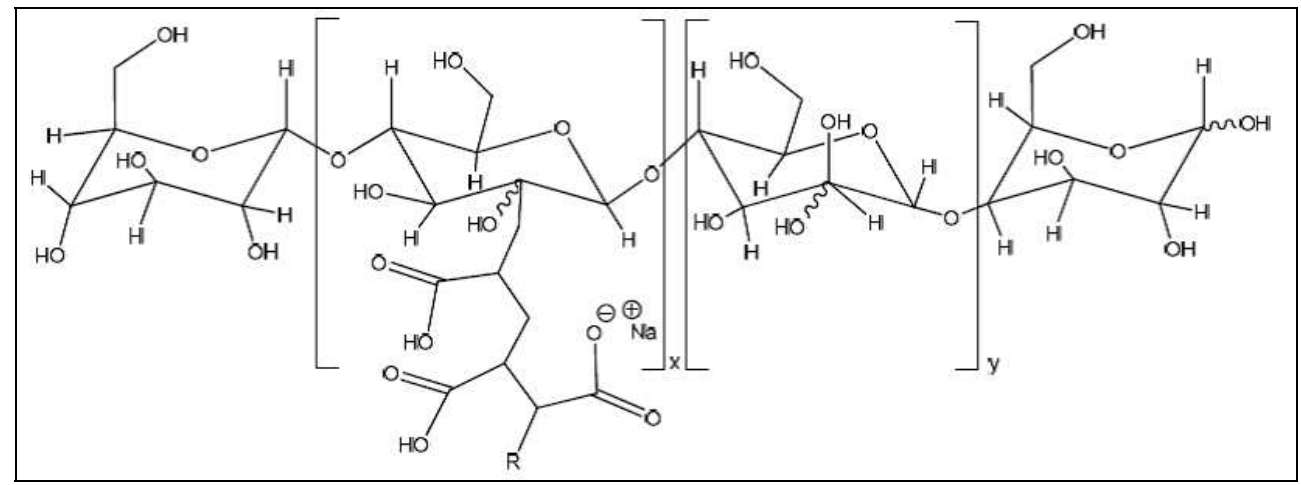

Fig. 9. AkzoNobel's hybrid polymers 
Upon receipt of target compounds can be used a wide range of synthetic monomers, and the polysaccharide framework gives different functional characteristics while preserving the key properties of inhibitors. Studies conducted by the company revealed additional benefits of hybrid polymers, such as biodegradable and nontoxic. In addition, they are more environmentally sustainable solutions for the inhibition of salt deposition than synthetic products and not accumulated by living organisms.

\begin{tabular}{|l|c|c|c|}
\hline Test (GLP standard) & Method & Result & Goal \\
\hline Bioaccumulation & OECD 107 & $\operatorname{lgP} \mathrm{ow}^{-2.95}$ & $\operatorname{lgP} \mathrm{ow}<2.95$ \\
\hline Acute toxicity - algae & $\mathrm{ISO} 10253$ & $\mathrm{EC}_{50}>100 \mathrm{mg} / 1$ & $\mathrm{EC}_{50}>100 \mathrm{mg} / 1$ \\
\hline Acute toxicity - halibut fry & OECD 203 & $\mathrm{LC}_{50}>100 \mathrm{mg} / 1$ & $\mathrm{LC}_{50}>100 \mathrm{mg} / 1$ \\
\hline Acute toxicity - acartia tonsa & ISO & $\mathrm{LC}_{50}>100 \mathrm{mg} / 1$ & $\mathrm{LC}_{50}>100 \mathrm{mg} / 1$ \\
\hline
\end{tabular}

Table 1. Biodegradability test results

These hybrid polymers are produced by more than $50 \%$ of renewable raw materials, as opposed to synthetic materials, and have lower emissions of carbon dioxide - hybridization reduces $\mathrm{CO} 2$ emissions by more than $50 \%$.

The company also points to the adaptability of the technology of synthesis of target compounds, which expands the possibilities for optimizing the properties of the products according to specified criteria.

The company Rhodia offers to use as an inhibitor of salt deposits (carbonates and sulfates of magnesium, calcium and barium) natural polysaccharide composed of mannose and galactose residues in the native form and after modification of the relevant reagents (Figure 10). It is noteworthy that such products are not only patented, and commercially available.

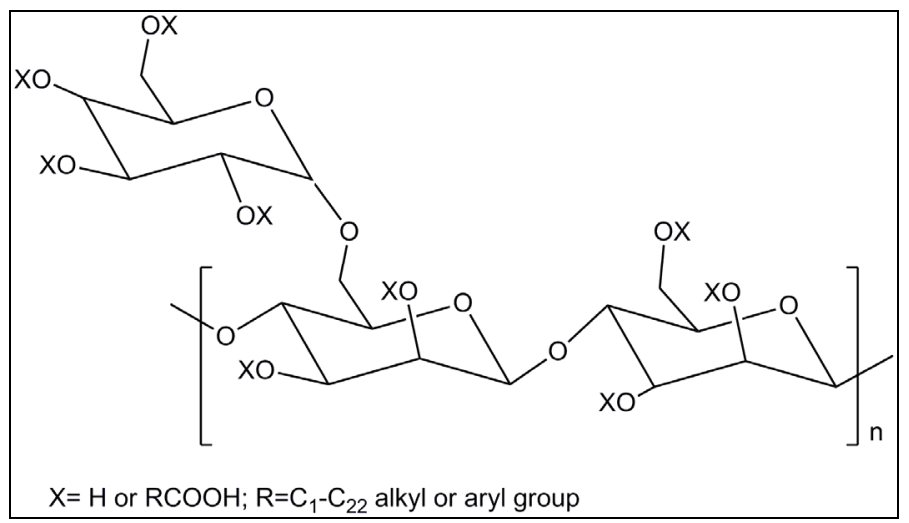

Fig. 10. Rhodia's polymeric scale inhibitors

It is also noted that in the future as raw material for production may be other polysaccharides: starch and cellulose. 


\subsection{Biocides}

Microorganisms that cause biological corrosion, play a significant role in the corrosion of underground oil, gas and water pipelines, corrosion of ship and aircraft equipment, metallurgy and metalworking equipment, chemical and food industries. Microorganisms act as corrosive agents mainly due to the aggressive production of metabolites and a corrosive environment. As an aggressive advocate of metabolites of organic and inorganic acids, enzymes, and hydrogen sulfide.

In many cases, the microbiological contamination is obvious, with visible signs include changes in color medium viscosity, presence of slime, sludge and other sediments. Less obvious indicators - the inefficiency of film-forming corrosion inhibitors and the presence of contaminants such as salts or iron oxides.

In the oil industry, the main agents of the corrosion process of metal fracture are sulfatereducing bacteria. They account for at least $90 \%$ of hydrogen sulfide entering the cycle of sulfur compounds that about $80 \%$ of all corrosion damage land and $50 \%$ damage of underground equipment. The economic costs of biological damage can be up to $3 \%$ of the metal structures are exploited.

Spectrum inhibitors, bactericides and fungicides used to suppress the activity of microorganisms is extremely varied, but among them are many toxicants not only to microorganisms but also to warm-blooded. For example found that benzotriazole is used as a bactericide has high toxicity to mammals, and some arthropods.

Among the aldehydes used in the manufacture of disinfectants found formaldehyde, glutaric and orthophthalic aldehydes having a broad spectrum of activity (Gram-positive and Gram-negative bacteria, fungi, mycobacteria, shell / implant failure viruses), including spores. Drugs, having in its composition glutaraldehyde get better, biocidal properties do not cause corrosion of materials of tools will not damage fabrics and surfaces are stable (which allows multiple solutions), have good penetration, fast destructible in wastewater. In fact, disinfectants on the basis of glutaraldehyde has been and remains the "gold standard" in many spheres of human activity. We can say that among the classes of oilfield chemicals biocides are the most "green" reagents.

\subsection{New types of oilfield chemicals}

\subsubsection{Reagents complex action}

Reagents complex action can perform several functions simultaneously, for example, act as a corrosion inhibitor and scale inhibitor. In this case, it is not a simple mixture of several substances, and about a component that performs both functions. As often occurs in oil fields, several adverse events (corrode equipment, salt deposition, the presence of sulfatereducing bacteria, etc.), the creation of such reagents can significantly reduce the costs of minimizing damage.

An example of a complex of the reagent is a corrosion inhibitor and scaling based on aspartic acid, proposed by Nalco. Synthesis is proposed to conduct a phase 2 (Figure 11). 


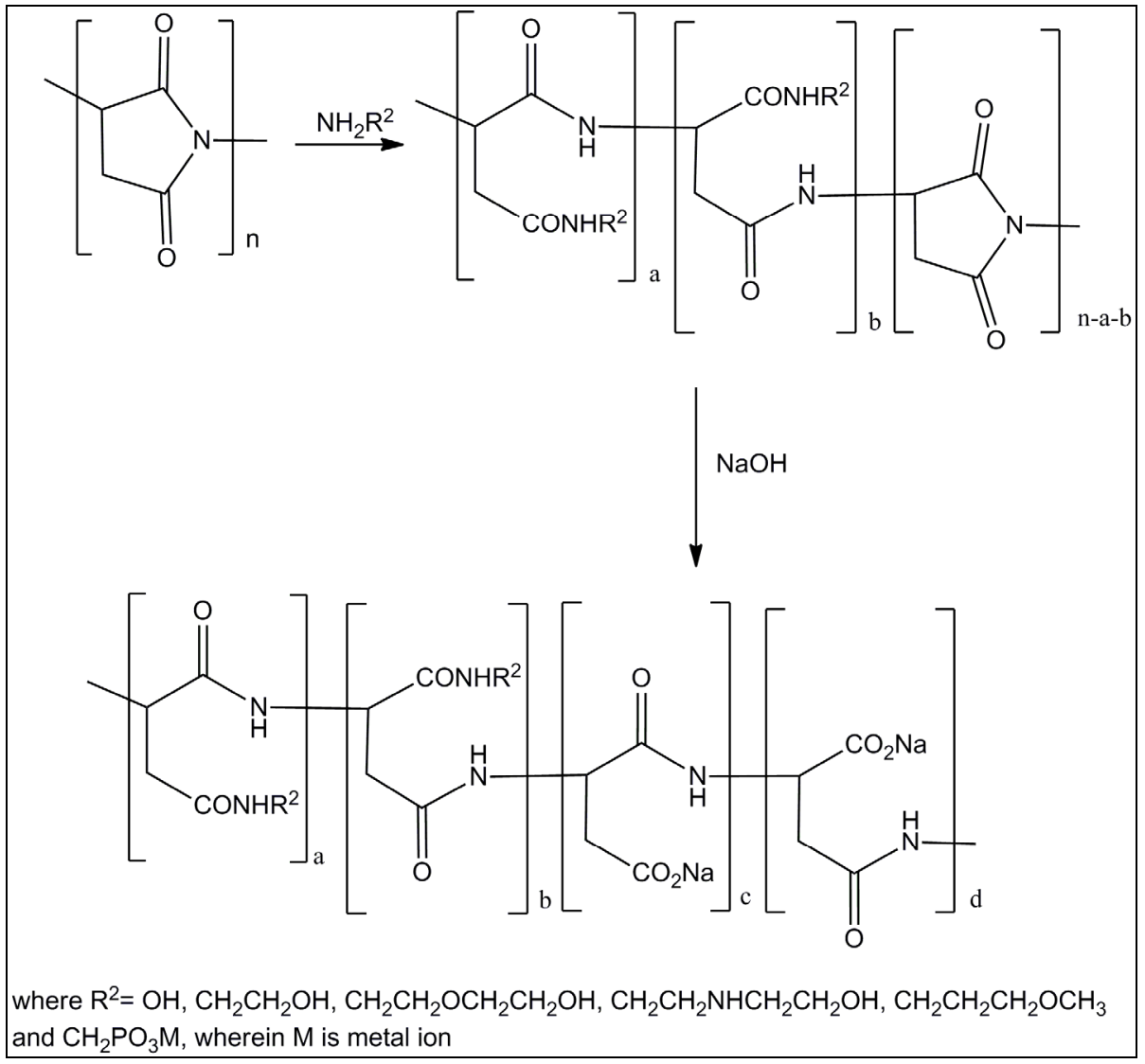

Fig. 11. Synthesis of the reagent complex action

Highlights not only the protective properties, and biodegradability of these products with polymeric structure.

\subsubsection{Encapsulated reagents}

Along with the creation of new reagents for oil production, become important technological methods of their use. Depending on the reagents can be used for the following technologies:

- $\quad$ by continuous or periodic supply to the system using metering devices;

- $\quad$ periodic injection of a solution into the well followed by his supply in bottomhole zone.

Consistently can be used combined methods of delivery reagent, for example, initially periodic injection, and then - after 2-6 months - a continuous or periodic supply dosage of reagent in annulus. 
Distribution is the method of periodic filing solution in annulus, but it is not efficient, since the low dynamic poles reagent quickly carried away by fluid flow. In the most favorable conditions of high dynamic frequency of feeding poles inhibitor is 15-20 days.

The method of dispensing reagents applied for maintenance of underground equipment and pipe elevator, but when there are problems in the bottomhole formation zone is necessary to supply into the reservoir. Dosing of reagent into the well (the system) is considered a reliable method, although it requires constant monitoring and maintenance of metering pumps and devices.

Disadvantage of the periodic injection of the solution in the annulus is that the process is accompanied by illuviation of reagent into the rock. A common shortcoming of these methods is too high consumption of reagent due to inefficiency of its use.

The use of submersible containers dispensers - the most economical and efficient way compared to others. The operating principle of these containers is based on different processes: dissolution, or leakage to the gravitational turbulent mixing of the reagent with the formation fluid. Submerged containers deliver reagent deep wells, where a minimal amount of active ingredient. However, the rate of dosing is determined by the downhole conditions, so the design of submerged container should be selected individually for each well. Usually this is not done or can not do so while the container is often different from the statements to the same dosing containers require special arrangements for their installation and maintenance.

It is now one of the most promising directions is the creation of microscopic containers, hoppers, the so-called microencapsulation reagent.

The advantages of using microencapsulated chemicals include:

- the possibility of long-acting agents required, as a consequence of the increase interservice interval;

- the possibility of joint use of substances of different classes that can react with each other for direct use;

- a longer residual effect of chemical treatment;

- a safer treatment with chemical agents;

- more simple equipment needed to handle well, the lower price, due to better control and less consumption of reagents;

The disadvantages of using such technology products are:

- tendency to adsorb on the capsule surface solids;

- reducing the duration of the reagent in the wells with high flow rates of fluids:

Microencapsulated product is a reagent, a prisoner in the polymer capsule. The reagent is pumped into the annulus, after which the capsules are deposited on the face. When operating the wells polymer membrane is dissolved, mixed with a liquid reservoir, providing a way out of the reagent.

Within 1-2 days after the product is well increased yield of reagent and then the system comes into equilibrium and its removal is lower (but above the minimum inhibitory concentration) and permanent. 
Exit the reagent is carried out by the concentration gradient. With increasing consumption of reagent in the external environment is intensifying its removal from the capsule, and vice versa when - flow of reagent bounces back - his removal from the capsule slows down.

Material for the microcapsules are hydrophilic colloidal materials:

- $\quad$ protein origin (gelatin, albumin);

- polysaccharide structure (alginates, such as sodium alginate, casein, agar-agar, starch, pectin, carboxymethylcellulose, and some other). To obtain such materials are usually used to form a microcapsule by coacervation. The preferred material for encapsulation is gelatin, which precipitated a salt such as sodium sulfate or ammonium sulfate, or involved in coacervation with polyanions, such as gum arabic (acacia), even more preferred is the use of compounds capable of crosslinking of the carrier material, such as formaldehyde or glutaraldehyde (Figure 12).

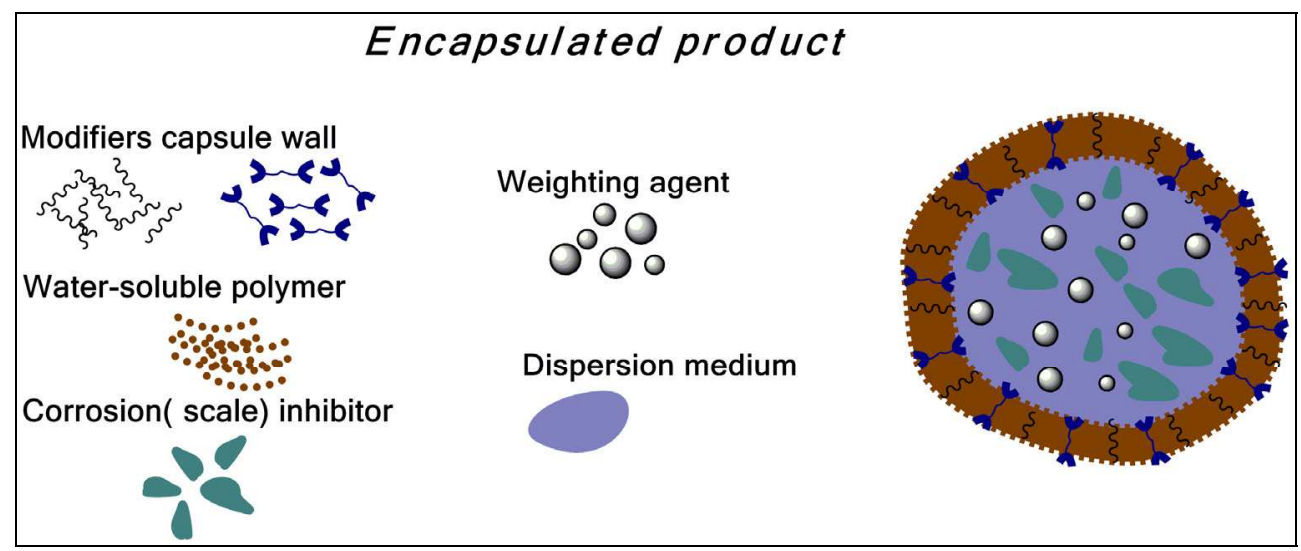

Fig. 12. Composition of the capsule

Encapsulated reagents offer oilfield companies such as Champion Technologies and Mirrico.

\section{Conclusion}

Thus, we can formulate the basic requirements for the product oil and gas industry in line with the standards of "green chemistry":

- High efficiency

- Availability

- Universality

- Environmental safety

- A sufficiently high rate of biodegradation into harmless substances

- Low cost.

However, the development and introduction of such products can be traced obvious difficulties. 
- To develop and test new recipes, rather strictly limited requirements of "green chemistry" can take quite a long time because it is theoretically and practically more Bole complex than simply the development of new agents without at least their biological hazards.

- Replacement of existing products with new chemical industry requires, as a rule, a significant restructuring of both the technological process and equipment used, which involve significant economic costs.

- $\quad$ Financial investment in scientific research to develop "green" products industry can be quite large, so you need constant monitoring and adjustment of balance between environmental safety, high effectiveness and cost of the desired product.

In recent years, clearly observed trends of developed countries identified the use of products "green chemistry" on the basis not only for reasons of environmental safety, development of similar products and technological schemes involves minimal risk to humans and nature, a more rational approach to the concept of obtaining a product, which ultimately account may lead to a significant reduction in price. Of course, this ideal case, but the examples in the modern chemical industry there that points to the undoubted promise of modern science and technology for "green" way, and it's not just a fad and a means of promoting new products, and a new stage of development of chemical technology, industry and science.

\section{Acknowledgment}

Authors would like to acknowledge to top managers of GC «Mirrico»: Malyhin I. and Ramazanov R.

\section{References}

Anastas, P. \& Warner, J. (1998). Green Chemistry: Theory and Practice, Oxford University Press, ISBN 0-198-50234-6, New York

Ash, M. \& Ash, I. (2004). Handbook of preservatives, Synapse Information Resources, ISBN-10 1890595667, Endicolt

Becker, J.(1998). Corrosion and scale handbook, PennWell Books, ISBN 0878147497, Tulsa

Durkee, J. (2006). Management of industrial cleaning technology and processes, Elsevier, ISBN-10 0080448887 Oxford

Lunin, V., Tundo, P. \& Lokteva, E. (2005). Green Chemistry in Russia, Poligrafica Venezia, ISBN 5-211-05001-0, Venezia

Sastri, V. (1998) Corrosion inhibitors: principles and applications, Willey, ISBN 0-471- 7608, New York

Schramm, L. (2000) Surfactants: fundamentals and applications in the petroleum industry, Cambridge University Press, ISBN 0-521-64067-9 Cambridge.

Karsa, D., \& Ashworth, R. (2002). Industrial biocides: selection and application, Royal Society of Chemistry, ISBN 0-854-04805-7, Cambridge

Scott, E., \& Gorman, S. (2001). Glutaraldehyde. Disinfection, sterilization and preservation, , Lippincott Williams\&Wilkins, ISBN 1-4051-0199-7, New-York. 
Cook, S. (1999). Green chemistry - evolution or revolution?. Green Chemistry, Oct. 1999, G138-G140.

Karabinos, J. \& Ballum, A. (1954). tall oil studies. II. Decolorization of polyethenoxy tallates with ozone and hydrogen peroxide J. Am. Oil Chem. Soc., Vol. 31 No 2, February 1954, pp. 71-74. 


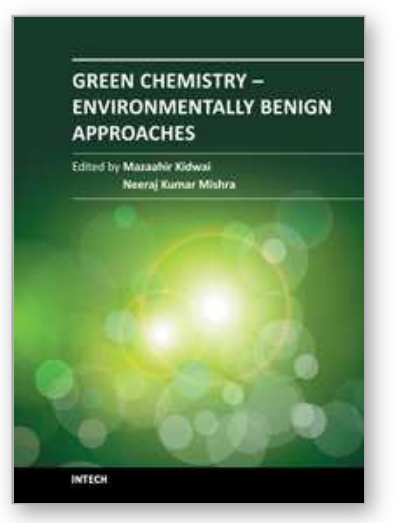

\author{
Green Chemistry - Environmentally Benign Approaches \\ Edited by Dr. Mazaahir Kidwai
}

ISBN 978-953-51-0334-9

Hard cover, 156 pages

Publisher InTech

Published online 23, March, 2012

Published in print edition March, 2012

Green chemistry is chemistry for the environment. It is really a philosophy and way of thinking that can help chemistry in research and production to develop more eco-friendly solutions. Green chemistry is considered an essential piece of a comprehensive program to protect human health and the environment. In its essence, green chemistry is a science-based non-regulatory and economically driven approach to achieving the goals of environmental protection and sustainable development. Combining the technological progress with environmental safety is one of the key challenges of the millennium. In this context, this book describes the environmentally benign approaches for the industries as well as chemical laboratories. In order to provide an insight into step change technologies, this book was edited by green organic chemists.

\title{
How to reference
}

In order to correctly reference this scholarly work, feel free to copy and paste the following:

Arkadiy Zhukov and Salavat Zaripov (2012). New Green Oil-Field Agents, Green Chemistry - Environmentally Benign Approaches, Dr. Mazaahir Kidwai (Ed.), ISBN: 978-953-51-0334-9, InTech, Available from: http://www.intechopen.com/books/green-chemistry-environmentally-benign-approaches/new-green-oil-fieldagents

\section{INTECH}

open science | open minds

\section{InTech Europe}

University Campus STeP Ri

Slavka Krautzeka 83/A

51000 Rijeka, Croatia

Phone: +385 (51) 770447

Fax: +385 (51) 686166

www.intechopen.com

\author{
InTech China \\ Unit 405, Office Block, Hotel Equatorial Shanghai \\ No.65, Yan An Road (West), Shanghai, 200040, China \\ 中国上海市延安西路65号上海国际贵都大饭店办公楼405单元 \\ Phone: +86-21-62489820 \\ Fax: +86-21-62489821
}


(C) 2012 The Author(s). Licensee IntechOpen. This is an open access article distributed under the terms of the Creative Commons Attribution 3.0 License, which permits unrestricted use, distribution, and reproduction in any medium, provided the original work is properly cited. 